\title{
THE MANAGEMENT OF THE CHRONIC ALCOHOLIC
}

\author{
By E. Lincoln Williams, M.R.C.S., L.R.C.P. \\ Medical Director, The Hall, Harrow Weald
}

It can now be stated fairly confidently that medicine has at long last recognized alcoholism as an illness, although we are very handicapped by the lack of a defined common aetiology of the disease. There still remain some who regard alcoholism as a bad and vicious habit and are convinced that moral failure is best dealt with by punitive measures. The pessimism, apathy, confusion of thought and practice of bygone years have largely been determined by wrongfully assessing alcoholics en masse, and to do so merely adds to the hoplessness of the situation and gives heightened effect to the stigma long associated with this illness. "Once a drunk, always a drunk' is almost proverbial. All workers in this field seem to agree that alcoholism is a constitutional malady allied to a personality disorder. The writer holds the view that so much depends on the personality of the patient prior to the onset of his excessive drinking. Four people may have the common factor of intoxication, but their treatment and prognosis depend on a psychiatric assessment of personality. Firstly, alcoholics of good previous personality as, for example, those who are happily married, sexually well-adjusted, efficient in their work, employed in the same firm for a number of years and therefore difficult to replace in their particular occupations, have over the years passed from social drinking to pathological compulsive drinking largely as a result of exogenous factors. Fundamentally normal men and women, apart from their drinking, their chances of recovery are highly promising, for they can be given an intelligent insight into their condition and their readiness to come to terms with their disability makes treatment of this type of alcoholic a hopeful project. The alcoholic with an underlying neurosis presents a different and more difficult problem. Alcohol to the neurotic is for him an escape par excellence from the reality of his maladjusted life -maladjusted long before he began drinking. He can only keep his spirits up by pouring spirits down! His alcoholism, therefore, has come about by endogenous factors in contrast to the patient of good previous personality. Treatment of the $\frac{2}{0}$ underlying neurosis by psychotherapy is essential, 3 needs very careful handling and is of course time- $\dot{\omega}$ consuming. To establish a satisfactory rapport $\underset{\omega}{\infty}$ with the patient the psychotherapist himself must of be a warmly human person. Moreover, the os neurotic alcoholic may easily become discouraged $\stackrel{N}{\circ}$ if he compares his own tardy progress with the 우 more rapid and stabilized recovery of the better $\rightarrow$ adjusted personality. The third type of alcoholic is one who presents all the usual signs of chronic intoxication, superimposed on a psychotic disorder which may only be recognized after the patient's admission to a mental hospital for the treatment of his alcoholism. Alcoholism at an early adult age of especially when it is accompanied by violent antie. social behaviour, makes one suspect the presence of a schizoid disorder. Some consider dipsomanic bouts to be factors of the manic-depressive syndrome. Treatment should be directed primarily to the underlying psychosis in a suitable environment and not towards the superadded alcoholism. Fourthly, if psychiatric investigation reveals an underlying psychopathic personality, responsibility and sincerity cannot be looked for. Genuine sincerity on the part of the patient with a real wish to recover is the touchstone of all treatment. The psychopath accepts no blame for the various misfortunes which befall him and which he brings down on those closely associated with him. Despite obvious evidence to the contrary, he denies that his drinking is a problem and is curiously ungrateful for the many efforts and sacrifices made on his behalf. The alcoholism is but one facet of a defective character make-up and experience has shown that it is well nigh impossible to treat it. The high incidence of psychopathy among alcoholics ${ }^{1}$ and the inevitable failure which attends the treatment of psychopathic social misfits, unfortunately lowers the recovery rate of all methods of treatment and brings them into disrepute. It is usually the aggressive type of psychopath who becomes an excessive drinker.

Diagnosis of a pyschopathic personality may be 
confirmed by an E.E.G., which often shows abnormal rhythms in all areas. The value therefore of a personality diagnosis to determine into which of the four categories the patient belongs'the good', 'the sad', 'the mad' or 'the bad'-is that it will assist in the selection of the therapy most likely to benefit the individual. Although there is now general acceptance of the concept of alcoholism as an illness, the alcoholic at first may not readily believe it to be so, and clings tenaciously to the idea that somehow, someday, he will regain control of the situation. Relapse after relapse, with declining health and the possible threat of divorce or dismissal from his job may ultimately force him to see the stark rea'ity of his drinking pattern.

It is often only when he has touched ' rock bottom ' that he is preapred to accept the fact that he has lost the ability to control his drinking. Despite the patient's stubborn unco-operative attitude the dostor should continue to stress the concept of alcoholism as an illness and not moral tailure. The futility of the patient's own efforts should be emphatically demonstrated to him. If, at this stage, he can be introduced to other a coholics who have made a successful recovery, his identification with them will prove to be of the utmost therapeutic importance.

Should the patient's drinking history reveal that he has become a true addictive or compulsive drinker, then treatment aimed at total and permanent abstinence must be instituted as soon as possible.

Where to treat the patient is a matter which should receive more thought and attention, for it would appear that alcoholics are best treated in special clinics, similar to those established in America. No one form of therapy, or combination of forms, claims a satisfactory recovery rate when tried on any considerable number of alcoholics. It would seem therefore that the secret of therapy lies, not so much in its nature, as in its application to each individual case. It has already been pointed out that alcoholics cannot be considered in the mass.

On admission, a though physical examination should be carried out to differentiate between organic disease directly attributable to excessive drinking, and disease resulting from other causes. Routine laboratory tests should be carried out, and an electrocardiogram where possible.

\section{Methods of Detoxication}

In the past detoxication has been carried out by immediate or part withdrawal of all alcohol, combined with sedation - usually paraldehyde, together with a liberal supply of fluids by mouth or intravenously.

Pullar-Strecker $^{2}$ suggested the simultaneous administration of small amounts of insulin and glucose, together with concentrated vitamins.

Lecoq $^{3}$ gives intravenous infusions of Curethyl, which contains alcohol and liver extract suspended in isotonic glucose. Alcohol given in this way does not intoxicate but detoxicates, strangely enough.

Smith $^{4}$ first introduced the treatment of alcoholic states by the administration of adrenocorticotropic hormone (ACTH) given intramuscularly in 25 mgm. doses, every six hours for 36 hours. This therapy was founded on the theory that delirium tremens is similar clinically and biochemically to Addisonian crisis or adrenal exhaustion. On the finding that alcohol given to rats caused a marked depresision of the adrenal ascorbic acid, it was held that the repeated stimuli of intoxication probably led to adrenal exhaustion. It is claimed that ACTH is the most effective treatment for delirium tremens, but there is little evidence that hormone therapy of this type in any way alleviates or relieves alcoholic craving.

Davis and Robertson ${ }^{5}$ suggested the administration of pure oxygen by mask for twenty minutes every hour for six hours, for patients suffering from acute alcoholic psychosis. The oxygen is continued hourly for $24-48$ hours, supported by the intravenous administration of insulin, glucose and vitamins to preserve adequate liver function. They claim that patients receiving this form of therapy need no sedation.

R. J. Williams ${ }^{6}$ in experimental work on alcohol consumption by rats, discovered that when the diet was deficient, especially in factors of the B Complex, the rats' consumption of alcohol increased. When, however, vitamins were added to the diet, the alcohol consumption decreased. As a result of this experiment it was decided to adminster various combinations of vitamins to patients suffering from chronic alcoholism, and it would appear that addiction, in many cases, was controlled so long as a liberal supply of vitamins was maintained. From these experiments it was hoped to establish that addiction was closely associated with some defect in metabolism, possibly inherited.

A recent and very important therapy is one described by Gould.? This consists of giving enormous doses of vitamins by rapid intravenous injection, or by rapid drip. A typical prescription (to be given by drip) is :

Glucose ro g. (10 per cent. solution). . $\quad 100 \mathrm{ml}$. Aneurine hydrochloride $\quad . . \quad \ldots \quad$ r,000 $\mathrm{mg}$. Nicotinamide .. $\quad$.. $\quad \ldots \quad$.. $200 \mathrm{mg}$. $\begin{array}{llllll}\text { Pyridexine } & \ldots & \ldots & \ldots & \ldots & 200 \mathrm{mg} \text {. }\end{array}$ Ascorbic Acid .. $\quad \ldots \quad$. . $\quad \ldots \quad$ 1,500 mg. Distilled water or normal saline solu-

tion to $\quad$. $\quad$.. $\quad$.. $250-300 \mathrm{ml}$. 
After the initial dose (which may be repeated if the patient does not respond satisfactorily) it is usual to give two more injections, each containing half the above amounts, at four-hourly to eighthourly intervals.

Wordsworth ${ }^{8}$ described the sobering-up effect of $100 \mathrm{mgm}$. of Vitamin $\mathrm{B}_{6}$ (Benadon) given intravenously. An excitable, noisy patient quietened down within three minutes of the injection. Martensen-Larsen ${ }^{9}$ utilising the known capacity of fructose to promote the metabolism of alcohol, combines this with Vitamin $B_{6}$. They supplement each other to produce a detoxicating and sedative effect.

Martensen-Larsen ${ }^{10}$ described the administration of disulfiram ( $7.5 \mathrm{mg}$. per kg.) together with $25 \mathrm{mg}$. of Promethazine, plus $5 \mathrm{~g}$. of sodium chloride, in half a tumbler of water. Antihistamines such as Promethazine seem to counteract the undesirable histamine-like cardiovascular effects of the disulfiram-alcohol reaction, while the sedation produced during the reaction is utilised. Martensen-Larsen further suggests that fructose, in the form of honey $125 \mathrm{~g}$., may very well be combined with the antabuse-antihistamine-sodium-chloride therapy.

In May of this year, Cummins and Friend ${ }^{11}$ described the use of chlorampromazine in the treatment of 60 patients suffering from chronic alcoholism. It is therapy designed to control the unpleasant symptoms of psychomotor agitation when alcohol is withdrawn. 'Symptoms may take the form of boisterousness, incoherent speech, clumsiness, tremulousness to a point where the patient may not be able to sit quietly, insomnia, changes in personality, hallucinations and sometimes frank psychotic episodes. The agitation gradually descreases over a number of days until the only complaint the patient has is a sensation of " butterflies in the stomach." These symptoms vary according to the individual and to the severity of the intoxication.'

An extensive physical examination is first of all carried out. Irrespective of the quantity of liquor consumed, patients are given simultaneously, 100 $\mathrm{mgm}$. of chlorampromazine and $500 \mathrm{mgm}$. of disulfram (Antabuse) by mouth. Within six hours, chlorampromazine $50 \mathrm{mgm}$. is repeated. Twentyfour hours later, $500 \mathrm{mgm}$. disulfram and $50 \mathrm{mgm}$. chlorampromazine are administered. Forty-eight hours following initial therapy, $500 \mathrm{mgm}$. disulfram and $25 \mathrm{mgm}$. chlorampromazine are prescribed. Thereafter for one week, $500 \mathrm{mgm}$. of disulfram is administered daily. The dosage of disulfram is then adjusted to the patient's tolerance, usually 0.25 or $0.5 \mathrm{gm}$. daily. It is claimed that disulfram and chlorampromazine, when administered together in: adequate dosage to the inebriated alcoholic, remove all the symptoms of pyschomotor agitation more effectively than with any current $\mathbb{\infty}$ method of sedation. Chlorampromazine is known in this country as Largactil. Further investiga- $\Rightarrow$ tions are taking place on the use of Largactil in this $\stackrel{\vec{O}}{\rightarrow}$ country, and the results are awaiting future publication.

\section{Disruption of the Drinking Pattern}

Physical treatments in current vogue are as follows:

Conditioned-Reflex Treatment, commonly called $\vec{\circ}$ aversion treatment, as described by Voegtlin and $\overrightarrow{\vec{\omega}}$ Lemere $^{12}$ of Seattle. This method consists in the ${ }^{\circ}$ attempt to arouse distaste for alcoholic beverages 0 by associating their taste with nausea and vomiting. 3

The establishment of the conditioned-reflex aversion to alcohol is undertaken during a number $\dot{\omega}$ of treatments (usually five to seven) with rest ${ }_{0}$ periods between. No sedatives should be given for 12 hours prior to each treatment. The treat- $\sigma$ ment room is darkened, except for the table with 은 its array of liquors, spotlighted from behind the bed. This attention to the visual sense will cause the sight of liquor to become one element of the $\mathbb{\Phi}_{\overparen{D}}$ conditioned stimulus. Similarly, by forcing the $\frac{1}{3}$ patient to smell deeply of various liquors at every possible opportunity during the treatment, the olfactory sense may also be utilised as still another element of the conditioned stimulus. Using there nauseant, Emetine, to elicit the unconditionedto reflex of nausea and vomiting, the sight, taste and smell of alcoholic drinks therefore serve as a conditioned stimulus, and thus a conditioned-reflex is established. Considerable experience of the $\stackrel{\mathbb{Q}}{\mathbb{2}}$ special technique is necessary to produce good $\overrightarrow{\vec{P}}$ results. This treatment is calculated to induce an $\frac{3}{3}$ aversion to alcohol, but there are some patients who never develop a true and lasting aversion, yet have maintained sobriety. It would seem therefore that the conditioned-reflex is not the whole answer

The physical debilitation brought about by the aversion treatment seems to be accompanied by a $\delta$ profound disruption of other aspects of the patient's personality, and a total change in outlook. Follow- 을 ing treatment, the patient is particularly amenable to simple and forceful psychotherapy, stressing his need for permanent sobriety, and his ability to achieve and maintain it.

Apomorphine. Dent ${ }^{13}$ and recently Feldman of $N$ Geneva, use apomorphine as a nauseant and $\mathrm{\omega}^{-}$ emetic, and give it in varying doses every few hours 0 for several days, either orally or parenterally. It is claimed that apomorphine removes the desire $\stackrel{0}{\Phi}$ for alcohol, but in no way produces a conditionedreflex aversion.

Antabuse. This treatment of alcoholism, as 
described by Jacobsen and Martensen-Larsen ${ }^{14}$ of Copenhagen, has now become an established therapy:' Acetaldehyde is formed under normal conditions after alcohol intake, by the ordinary process of oxidation. After treatment with Antabuse, blood acetaldehyde is increased to a concentration five to ten times higher than that seen when the same doses of alcohol are given to untreated individuals. Antabuse plus alcohol produces an intense vasoldilatation of the face and neck, giving the patient a purple-red appearance. The pulse rate is rapidly increased to 120 to 140 , and there is a definite smell of acetaldehyde in the breath. There is subjective dyspnoea, and later in the treatment nausea and vomiting may occur. Antabuse is taken daily over several months, but the sincerity of the patient here, as in other forms of therapy is of paramount importance. It is vitally important for patients undergoing this form of therapy to be under strict medical supervision.

In all cases it is important to provide a nutritious diet, fortified by vitamins. Hepatic dysfunction requires a high calorie, high protein and high carbohydrate diet.

It would appear that at the present state of our knowledge whichever therapy is employed, good results are only obtained in about half of the total number treated.

\section{Anxiety-Tension States}

The alcoholic with an underlying neurosis frequently suffers from recurrent anxiety-tension states which demand alcohol to relieve them, since alcohol is a sedative and not a stimulant. Some interesting work has been carried out by Conachy ${ }^{15}$ in the treatment of these tension states by subconvulsive-electrostimulation. In a paper awaiting publication in the British Fournal of Addiction, Lady Frankau and Conachy have collaborated together to give further evidence of the very real value of this form of therapy.

Subconvulsive-electrostimulation consists of passing an alternating current of 40 to $50 \mathrm{~mA}$. through the brain in an attempt to stimulate the emotional centres in the diencephalon. This treatment must always be carried out under general anaesthesia, using Thiopentone .5 to $.9 \mathrm{gm}$. intravenously, combined with atropine grs. 1/100 to minimize vagal inhibition. Nickel electrodes with pads soaked in saline are placed $\frac{1}{2}$ in. anterosuperiorly above the ear, and the current is slowly raised, using a glissando technique. Respiration is re-established from $\frac{1}{2}$ to $I$ minute, and the current is administered from 5 to 6 minutes, the intensity of the current being gradually reduced during this period. The patient may wake up with an emotional reaction and be particularly receptive to psychotherapy, or he may fall into a deep sleep with a marked sense of relaxation and freedom from tension on waking.

\section{Group Therapy}

Following treatment, alcoholics should be urged to join a group either under the supervision of a psychiatrist, or the group therapy provided by Alcoholics Anonymous. Alcoholics Anonymous is a fellowship of men and women who have banded together to help each other maintain sobriety. It has been found by members that remaining anonymous ensures the placing of principles above personalities. This organisation, which was founded in America 16 years ago, now flourishes in 34 countries of the world, and is proving itself an invaluable ally to our profession.

Identification with a group of other sufferers whose drinking history so closely resembles their own, fortifies the desire and the need to maintain total sobriety. This applies not only to patients who have finished treatment, but the newly admitted patient should also be encouraged to mix with his fellows in an atmosphere of complete frankness of discussion, and of friendly concern for each others affairs. This identification helps to disperse harmful reserve and a sense of shame. Every effort should be made to help the patient reconstruct his life. The patient's family must be encouraged to accept the concept of alcoholism as an illness. His social and business contacts too, should be instructed in the nature and complexities of the illness, in order to help him to re-establish himself, free from wariness and distrust.

The alcoholic will need also the help and the true understanding of those who profess the way of God. He is more likely to achieve and maintain total sobriety if he accepts and depends on a saving power outside himself. The Alcoholics Anonymous programme embodies this same principle. Moral re-armament suggests that 'a pursuit of evil can only be met by a pursuit of good.' The alcoholic, but more often his immediate family, seek the help of the sacred minister before consulting a doctor. On this point, Professor Levy ${ }^{16}$ says, ' The scientific approach by no means excludes the moral. On the contrary, the approaches are complementary, and medicine should regard moral suasion in the same way as moral suasion considers scientific knowledge, namely as an ally in a common task . . . if the clergyman can successfully persuade a person indulging in too much drink to regard this as an evil from the moral point of view and, if his will power is not yet sufficient, to seek advice and treatment from a doctor or psychiatrist, moral suasion has initiated the first step towards the application of modern science to the alcoholic.'

A disciplined 'stone cold' sobriety is not enough, and would at best be a precarious existence. 
By developing his spiritual resources and by helping others similarly afflicted, he will gradually gain emotional maturity:

So much has yet to be learned about this complex problem with all its social implications, that it clearly calls for further enlightenment of public opinion, further medical research, and the provision of greater facilities for treatment in special alcoholic clinics. When these various measures are fulfilled, we shall be able to approach the alcoholic and his treatment with greater confidence, and alcoholics need no longer be anonymous.
REFERENCES

'WILLIAMS, L. (1952), Lancet, i, 787

2PULLAR-STRECKER, H. (I945), Brit. \%. Inebr., 43, 14-38. ${ }^{3}$ LECOQ, R. (1948), C. R. Soc. Biol. (Paris), 142, 893.

"SMITH, J. J. (1950), Quart. F. Stud. Alc., 2, 190.

'DAVIS, C. N. and ROBERTSON, H. F.' (r949), Quart. F. Stud, Alc., ro, 59-62.

'WILLIAMS, R. J. (195I), 'Nutrition and Alcoholism.'

${ }^{7}$ GOULD, J. (1053), Lancet, i, 570

sWORDSWORTH, V. P. (1053), Brit. med. F., (April 25), 935

'MARTENSEN-LARSEN, O. (1954), Ibid., (Äugust 3I), 464.

10MARTENSEN-LARSEN, O. (1953), Quart. F. Stud. Alc., 14, 406. ज

${ }^{11}$ CUMMINS, J. F. and FRIEND, D. G. (1954), Amer. F. Med. Sci., $227,561$.

${ }^{12}$ VOEGTLIN, W. L. and LEMERE, F. (1942), Ibid., 203, 525

${ }^{13}$ DENT, J. Y. (I94I), 'Anxiety and its Treatment.' London.

'JACOBSEN, E. and MARTENSEN-LARSEN, O. (I949), $\mathcal{F}$ Amer. Med. Ass., 139, $018-922$

15PATERSON, A. S. and CONACHY, A. (1952), ii, 1170

'LEVY, H. (195I), ' Drink.' London.

\section{OBSTETRICS \& GYNAECOLOGY}

(Postgraduate Medical Journal, July, 1954)

Price : 3s. 8d., past free

\section{INTRODUCTORY}

Charles D. Read, F.R.C.S., F.R.C.O.G.

RESPIRATORY HAZARDS IN THE PREMATURE INFANT

Albert E. Claireaux, M.D., M.R.C.P.

POSTMATURITY

S. G. Clayton, M.D., M.S., F.R.C.O.G.

THE RELATIVE MERITS OF THE VARIOUS BIOLOGICAL TESTS FOR PREGNANCY

H. P. Ferreira, M.D.

\section{PELVIC THROMBOSIS}

J. Stallworthy, F.R.C.S., F.R.C.O.G.

THE EARLY DIAGNOSIS OF GENITAL CANCER BY CYTOLOGY

Erica Waechtel, M.D.

THE MENOPAUSE

G. I. M. Swyer, D.M., M.R.C.P.

THE PLACE OF ULTRA-RADICAL SURGERY IN ADVANCED MALIGNANT DISEASE IN THE PELVIS

J. B. Blaikley, F.R.C.S., F.R.C.O.G.

Published by

THE FELLOWSHIP OF POSTGRADUATE MEDICINE

60, Portland Place, London, W.1

H. K. LEWIS \& Co. Ltd.

Medical Publishers and Booksellers

\section{GOWER STREET LONDON, W.C. 1} (Adjoining University College and Hospital)

Telephone: EUSton 4282 (7 lines)

Telegrams : Publicavit, Weatcent, London Established 1844

\section{Medical Lending Library}

ANNUAL SUBSCRIPTION from TWENTY-FIVE SHILLINGS

Prospectus post free on application

Bi-monthly List of New Books and New Editions added to the Library sent post free on request

The Library Catalogue revised to December, 1949, containing a classified index of authors and subjects.

To subscribers 17/6 net; To non-subscribers 35/- net. Postage 1/6

Supplement 1950 to 1952 . To subscribers $3 /$ - net; to nonsubscribers 6/- net; postage 6d.

NEW BOOKS ADDED IMMEDIATELY UPON PUBLICATION 